Article

\title{
Effect of Oxygen Supply on Surfactin Production and Sporulation in Submerged Culture of Bacillus subtilis Y9
}

\author{
Sanghyun Ha ${ }^{1,2}$, Ho Myeong Kim ${ }^{1}$, Ho Hyun Chun ${ }^{1}$, In Min Hwang ${ }^{1}$, Jong-Hee Lee ${ }^{1}$, \\ Jin-Cheol Kim ${ }^{2}$, In Seon Kim ${ }^{2}$ and Hae Woong Park ${ }^{1, *}$ \\ 1 Research and Development Division, World Institute of Kimchi, Gwangju 61755, Korea; \\ coolerha@wikim.re.kr (S.H.); hmkim@wikim.re.kr (H.M.K.); hhchun@wikim.re.kr (H.H.C.); \\ imhwang@wikim.re.kr (I.M.H.); leejonghee@wikim.re.kr (J.-H.L.) \\ 2 Division of Applied Bioscience and Biotechnology, Chonnam National University, Gwangju 61186, Korea; \\ kjinc@chonnam.ac.kr (J.-C.K.); mindzero@chonnam.ac.kr (I.S.K.) \\ * Correspondence: haewoong@wikim.re.kr; Tel.: +82-62-610-1728
}

Received: 25 July 2018; Accepted: 11 September 2018; Published: 14 September 2018

check for updates

\begin{abstract}
Fermentation parameters for surfactin production and sporulation in a submerged culture of Bacillus subtilis Y9 with various oxygen transfer rates in $5 \mathrm{~L}$ jar fermenters were investigated. The oxygen-uptake rate (OUR) was positively correlated with volumetric surfactin productivity. When OUR value increased from 0 to $250 \mathrm{~s}^{-1}$, productivity increased up to $45 \mathrm{mg} / \mathrm{L} \cdot \mathrm{h}$; however, no further increase was observed at OUR values above $255 \mathrm{~s}^{-1}$. The volumetric mass transfer coefficient $K_{L} a$ increased with increasing agitation speed. However, a reduction in surfactin production was observed at the highest agitation speed of $500 \mathrm{rpm}$. Productivity sharply decreased after spore appearance, and remained low until the end of the culture. A mesh-type sparger was installed to generate microsized air bubbles. When the system was operated at $400 \mathrm{rpm}$ with the mesh-type sparger, $K_{L} a$ was higher than that at $500 \mathrm{rpm}$ with an original sparger. Under agitation at $400 \mathrm{rpm}$ with the mesh-type sparger, productivity was maintained above $42.3 \mathrm{mg} / \mathrm{L} \cdot \mathrm{h}$ until $24 \mathrm{~h}$, resulting in the highest surfactin concentration of $875 \mathrm{mg} / \mathrm{L}$. Thus, a mesh-type sparger promotes $K_{L} a$, leading to an increase in productivity.
\end{abstract}

Keywords: Bacillus subtilis Y9; mesh-type sparger; oxygen-uptake rate; surfactin; volumetric-mass transfer rate

\section{Introduction}

Biosurfactants are surface-active compounds that are produced by various micro-organisms, e.g., bacteria, yeast, and fungi [1,2]. Their amphipathic characteristics make it possible to enhance the solubility of hydrophobic organic materials, leading to various applications to detergents, emulsions, dispersion systems, fabric softeners, and paints over food texture [3,4]. Compared to chemical surfactants, biosurfactants show several advantages, i.e., high bioavailability, biodegradability, and low toxicity.

Surfactin is a lipopeptide biosurfactant that consists of four isomers, i.e., surfactin A-D, with different chain length and branches of its hydroxyl fatty acid components. It is mainly produced by a rod-shaped Gram-positive bacterium, Bacillus subtilis, and shows biological potential for antimicrobial, antiviral, and insecticidal activities [5,6]. However, it has not been industrialized because of the high cost of production and purification [7]. Although the cost competitiveness of surfactin is lower than that of chemical surfactant, it should be used in some high-value products such as cosmetics, medicine, and biocontrol agents, due to increasing demand for safety. 
From an industrial point of view, high surfactin productivity in a submerged culture of B. subtilis is necessary to step forward toward commercial production. Various fermentation strategies, e.g., strain development, media optimization, trace-element optimization, fermentation types, reactor design, and cultivation conditions, were investigated to increase surfactin yield [8]. Among these parameters, the cultivation conditions of dissolved oxygen and oxygen-transfer efficiency have been actively investigated for surfactin production. Sufficiently dissolved oxygen had a positive effect on surfactin concentration in the submerged culture of B. subtilis [9-11]. Increases in agitation speed resulted in increasing oxygen-transfer efficiency and surfactin yield. However, the accumulation of foam at high agitation speed resulted in poor surfactin productivity, limiting the increase of agitation speed in the vessel [8].

We previously isolated the surfactin-producing B. subtilis Y9 [6], whose culture filtrate contained surfactin isomers $\left(\mathrm{C}_{14}\left[\mathrm{Leu}_{7}\right], \mathrm{C}_{14}\left[\mathrm{Val}_{7}\right]\right.$, and $\left.\mathrm{C}_{15}\left[\mathrm{Leu}_{7}\right]\right)$. In this study, B. subtilis $\mathrm{Y} 9$ fermentation parameters, including oxygen-uptake rate, oxygen supply, volumetric productivity, and sporulation, were investigated under various agitation speeds. In addition, the effect of the use of equipment to enhance oxygen supply on the parameters was investigated to enhance surfactin concentration in the submerged culture of B. subtilis Y9.

\section{Materials and Methods}

\subsection{Micro-Organisms and Media}

The B. subtilis Y9 strain was used to produce surfactin [6]. The fermentation medium consisted of $3 \%(w / v)$ galactose (Daejung, Siheung, Korea), $4 \%(w / v)$ yeast extract (Angest, Hubei, China), $0.25 \%(w / v) \mathrm{KH}_{2} \mathrm{PO}_{4}$ (Ducksan, Ansan, Korea), and $0.1 \%(w / v) \mathrm{NaCl}$ (Ducksan, Ansan, Korea) in distilled water. For maintenance of the strain, spores from a 5 day culture on tryptic soy agar (Sigma-Aldrich, St. Louis, MO, USA) were harvested, suspended in $1.2 \mathrm{~mL}$ cryovial tubes (Simport, Beloeil, QC, Canada) containing 20\% glycerol (Duksan, Ansan, Korea), and stored at $-70{ }^{\circ} \mathrm{C}$ to avoid genetic mutation due to successive culturing.

\subsection{Cultivation}

For seed cultures, a cryovial tube of B. subtilis $\mathrm{Y} 9$ was thawed at $25^{\circ} \mathrm{C}$ and the bacteria were cultured in $500 \mathrm{~mL}$ Erlenmeyer flasks containing $100 \mathrm{~mL}$ of tryptic soy broth (Sigma-Aldrich, St. Louis, MO, USA). The flasks were incubated in a rotary shaker at $200 \mathrm{rpm}$ (IS-971RF; Jeiotech, Daejeon, Korea) at $30{ }^{\circ} \mathrm{C}$ for $12 \mathrm{~h}$. For $5 \mathrm{~L}$ scale fermentation, $2 \%(v / v)$ of seed culture was inoculated in a jar bioreactor (MARADO-05D-XS, BioCnS, Daejeon, Korea) containing $3 \mathrm{~L}$ of fermentation medium and equipped with a dissolved oxygen meter (InPro6820/12/220, Mettler Toledo, Greifensee, Switzerland) and a pH meter (InPro3030/12/220, Mettler Toledo, Greifensee, Switzerland). Cultivations with an original sparger were carried out at $30^{\circ} \mathrm{C}$ for $48 \mathrm{~h}$, with agitation speeds ranging from 300 to $500 \mathrm{rpm}$ and an aeration rate of $1.0 \mathrm{vvm}$ (volume of air added to liquid volume per minute). In addition, a mesh-type sparger (CNS-A302, BioCnS, Daejeon, Korea) was installed to generate $10 \mu \mathrm{m}$ air bubbles. Cultivations with the mesh-type sparger were carried out at an agitation speed of $400 \mathrm{rpm}$ and an aeration rate of $1.0 \mathrm{vvm}$.

\subsection{Measurement of Surfactin}

The culture broth of B. subtilis Y9 was centrifuged at $16,000 \times g$ (5810R, fixed-angle type; Eppendorf, New York, NY, USA) for $5 \mathrm{~min}$, serially diluted, and filtered through a $0.45 \mu \mathrm{m}$ Polytetrafluoroethylene (PTFE) syringe filter (Whatman, Pittsburgh, PA, USA). The amount of surfactin was measured by High Pressure Liquid Chromatography (HPLC) (e2695 system; Waters Corp., Milford, MA, USA) using a C18 column ( $5 \mu \mathrm{m}, 4.6 \times 250 \mathrm{~mm}$; Waters). Elution was carried out isocratically using $20 \%$ $(v / v)$ trifluoroacetic acid and $80 \%(v / v)$ acetonitrile. The flow rate and detection wavelength were 
$1.0 \mathrm{~mL} / \mathrm{min}$ and $205 \mathrm{~nm}$, respectively. Surfactin (Sigma, St. Louis, MO, USA) was used as a standard and was quantified on the basis of a standard curve.

\subsection{Determination of Dry Cell Weight}

Ten milliliters of culture broth was centrifuged at $16,000 \times g$ (5810R, fixed-angle type; Eppendorf, New York, NY, USA) for $5 \mathrm{~min}$. Cell precipitates were washed 3 times with $10 \mathrm{~mL}$ of $0.9 \%$ saline solution, centrifuged, and placed in a plastic dish. The dishes were placed in a dry oven (VS-120203; Vision, Seoul, Korea) at $75^{\circ} \mathrm{C}$ for $24 \mathrm{~h}$. Dry cell weight was calculated as the difference between the weight of the dishes before and after drying.

\subsection{Determination of Reducing Sugars}

The concentration of reducing sugars was determined by a dinitrosalicylic acid assay [12]. The reagent was prepared as follows: $0.25 \mathrm{~g}$ of 3,5-dinitrosalicylic acid (Sigma-Aldrich, St. Louis, MO, USA), 75 g Rochelle salts (sodium potassium tartrate; Sigma-Aldrich, St. Louis, MO, USA), and $4 \mathrm{~g}$ $\mathrm{NaOH}$ (Sigma-Aldrich, St. Louis, MO, USA) were dissolved in $300 \mathrm{~mL}$ of distilled water. The reagent was purged with nitrogen gas prior to use. The culture broth of $B$. subtilis $Y 9$ was centrifuged at $16,000 \times g$ for $5 \mathrm{~min}$ to remove the cells, and the supernatant was filtered through a $0.45 \mu \mathrm{m}$ PTFE syringe filter (Whatman, Pittsburgh, PA, USA). One hundred microliters of filtered supernatant was added to $1 \mathrm{~mL}$ of the reagent. The reaction mixture was boiled in a water bath for $10 \mathrm{~min}$, transferred to an ice bath to cool down, and placed at room temperature. Absorbance at $570 \mathrm{~nm}$ was determined using a spectrophotometer (UV-1800; Shimadzu, Tokyo, Japan).

\subsection{Endospore Staining}

Based on the Schaeffer-Fulton staining method [13], spores were stained to investigate the effect of agitation speed on the spore ratio. The culture broth of B. subtilis $Y 9$ was serially diluted. B. subtilis $Y 9$ broth $(5 \mu \mathrm{L})$ was poured in a glass slide, fixed with heat, and covered with blotting paper. The paper was saturated with $0.5 \%(w / v)$ malachite-green stain solution (Kanto Chemical, Tokyo, Japan) for $5 \mathrm{~min}$, steamed over a container of boiling water, and washed with distilled water. The glass was counterstained with $0.25 \%(w / v)$ safranin (Sigma, St. Louis, MO, USA) for $30 \mathrm{~s}$ and washed with distilled water. Spores (bright green) and vegetative cells (pink) were distinguished by microscopic observation (IX73; Olympus, Tokyo, Japan).

\subsection{Determination of the Volumetric Mass Transfer Rate ( $\left.K_{L} a\right)$ and Oxygen-Uptake Rate (OUR)}

$K_{L} a$ is one of the important factors in aerobic fermentation. The material balance for dissolved oxygen in a liquid phase can be established with Equation (1) [14]:

$$
d C_{L} / d t=K_{L} a\left(C^{*}-C_{L}\right)-q_{O 2} X
$$

where $d C_{L} / d t$ is the rate of change in dissolved oxygen concentration, $K_{L}$ is the liquid film oxygen-transfer coefficient $(\mathrm{cm} / \mathrm{h}), a$ is the gas-liquid interfacial area per unit volume of liquid $\left(\mathrm{cm}^{2} / \mathrm{cm}^{3}\right), C^{*}$ is the saturated dissolved oxygen concentration in the broth $(\mathrm{mg} / \mathrm{L}), C_{L}$ is the actual dissolved oxygen concentration in the broth $(\mathrm{mg} / \mathrm{L}), q_{\mathrm{O} 2}$ is the specific oxygen-consumption rate ( $m g \mathrm{O}_{2} / \mathrm{g}$ dry cell weight $\cdot \mathrm{h}$ ), and $X$ is the cell concentration ( $\mathrm{g}$ dry cell weight/L). Dissolved oxygen tension (DOT), which is the partial pressure of oxygen molecules dissolved in the broth, was measured by using a dissolved-oxygen meter. When $d C_{L} / d t=0$, the material balance changes according to Equation (2):

$$
q_{\mathrm{O} 2} X=K_{L} a\left(C^{*}-\bar{C}_{L}\right)
$$


where $\bar{C}_{L}$ is the saturated dissolved oxygen concentration during reoxygenation $(\mathrm{mg} / \mathrm{L})$. Substituting Equation (2) with Equation (1) gives:

$$
d C_{L} / d t=K_{L} a\left(\bar{C}_{L}-C_{L}\right)
$$

Assuming that $K_{L} a$ is constant over time, Equation (3) can be integrated between $t_{1}$ and $t_{2}$ :

$$
K_{L} a\left(t_{2}-t_{1}\right)=\ln \left(\left(\bar{C}_{L}-C_{L 1}\right) /\left(\bar{C}_{L}-C_{L 2}\right)\right)
$$

where $C_{L 1}$ and $C_{L 2}$ are the actual dissolved oxygen concentration during reoxygenation $(\mathrm{mg} / \mathrm{L})$ at $t_{1}$ and $t_{2}$, respectively. $K_{L} a$ can be estimated from the slope when $\ln \left(\left(\bar{C}_{L}-C_{L 1}\right) /\left(\bar{C}_{L}-C_{L 2}\right)\right)$ is plotted against $\left(t_{2}-t_{1}\right)$.

OUR was calculated as the slope of the plot of dissolved oxygen concentration during temporary interruption of air supply to the bioreactor.

\subsection{Statistical Analysis}

Data were analyzed using PASW software (Ver. 17; SPSS Inc., Chicago, IL, USA). Analysis of variance (ANOVA), followed by the Bonferroni test, were used to determine significant differences between treatments at $p<0.05$.

\section{Results}

\subsection{Batch-Fermentation Characteristics at Different Agitation Speeds}

Surfactin-production profiles varied with varying agitation speeds of 300-500 rpm, which directly affected DOT throughout the culture (Figure 1). DOT levels at 300-500 rpm decreased sharply in the exponential stage of the culture, with less than $5 \%$ of DOT at $12 \mathrm{~h}$. At $500 \mathrm{rpm}$, DOT recovered to over $50 \%$ after $28 \mathrm{~h}$, while a negligible DOT level was maintained throughout the culture at 300-400 rpm. However, variability in surfactin production under different agitation speeds differed from the patterns in the DOT levels. The highest concentration of surfactin of $734 \mathrm{mg} / \mathrm{L}$ was observed at $400 \mathrm{rpm}$, followed by $619 \mathrm{mg} / \mathrm{L}$ at $500 \mathrm{rpm}$, and $453 \mathrm{mg} / \mathrm{L}$ at $300 \mathrm{rpm}$. Both the concentration and volumetric productivity of surfactin were determined by agitation speed in the first half of the culture. Surfactin concentration increased with the increment of agitation speed, especially from $12 \mathrm{~h}$ to $24 \mathrm{~h}$. Volumetric productivities were maintained above $16 \mathrm{mg} / \mathrm{L} \cdot \mathrm{h}$ during that time. After $24 \mathrm{~h}$, the productivities sharply decreased in order of agitation speed, with rates barely being over $10 \mathrm{mg} / \mathrm{L} \cdot \mathrm{h}$ until $32 \mathrm{~h}$ at $300 \mathrm{rpm}, 28 \mathrm{~h}$ at $400 \mathrm{rpm}$, and $20 \mathrm{~h}$ at $500 \mathrm{rpm}$, respectively. 


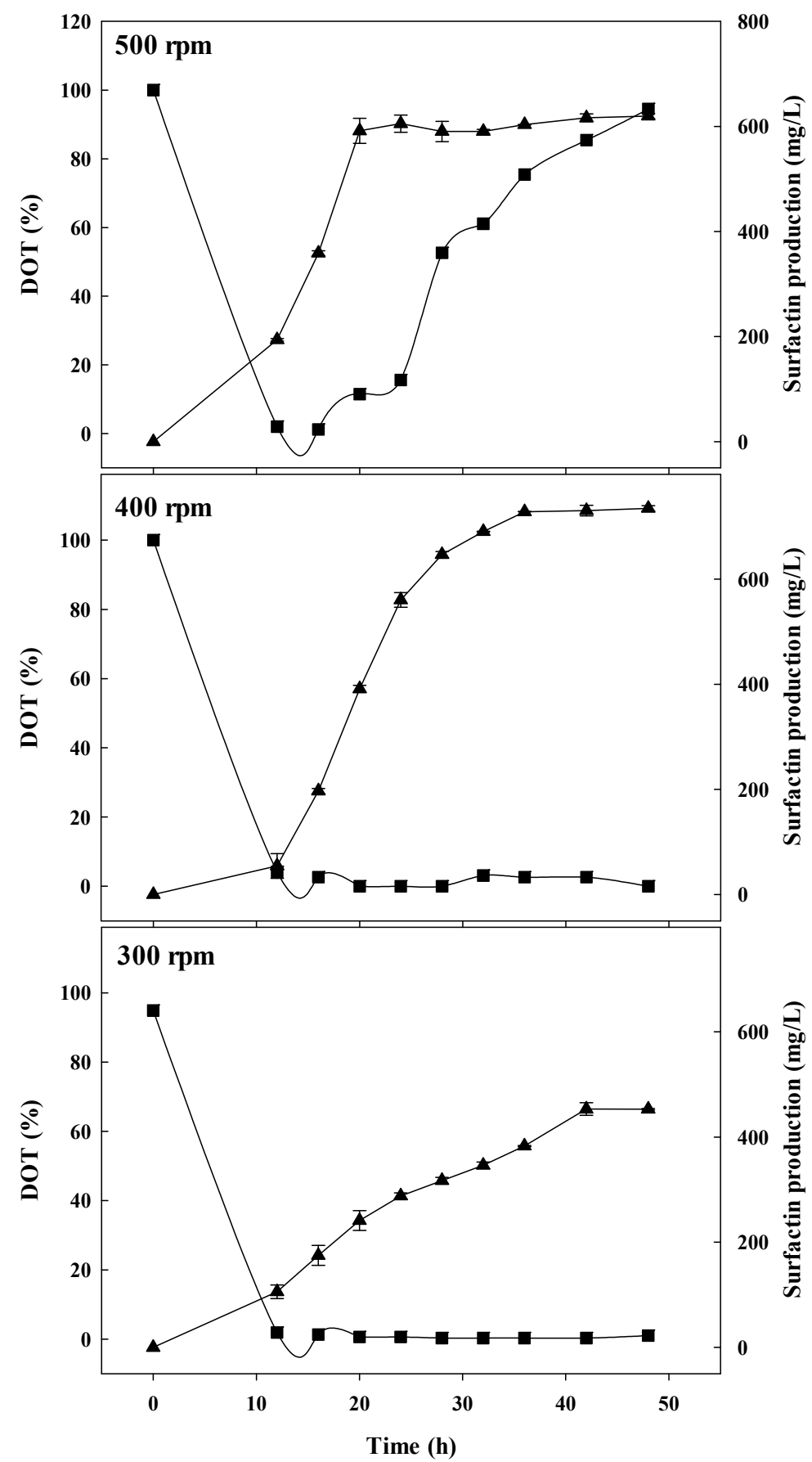

Figure 1. Surfactin production depends on agitation speed. Cultivations were carried out in $5 \mathrm{~L}$ jar fermenters for $48 \mathrm{~h}$. Filled triangle, surfactin; filled square, dissolved oxygen tension (DOT).

OUR was positively correlated with volumetric surfactin productivity (Figure 2). When the OUR value increased from 0 to $250 \mathrm{~s}^{-1}$, volumetric productivity increased up to $45 \mathrm{mg} / \mathrm{L} \cdot \mathrm{h}$; however, no further increase was observed in proportion to volumetric productivity when the OUR value was above $255 \mathrm{~s}^{-1} . K_{L} a$ increased with increasing agitation speed $(\mathrm{F}=133.5, d f=2.15, p<0.001)$ (Figure 3). The highest $K_{L} a$, of $0.0235 \mathrm{~s}^{-1}$, was observed at $500 \mathrm{rpm}$, followed by $0.177 \mathrm{~s}^{-1}$ at $400 \mathrm{rpm}$, and $0.0138 \mathrm{~s}^{-1}$ at $300 \mathrm{rpm}$. 


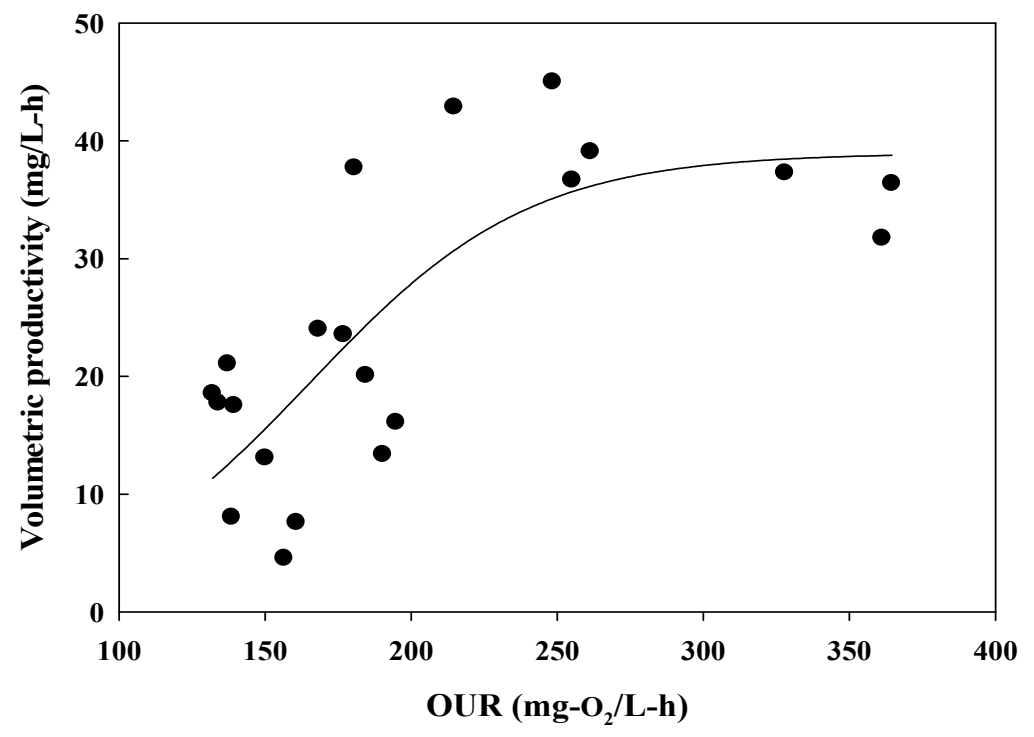

Figure 2. Relationship between oxygen uptake rate (OUR) and volumetric surfactin productivity.

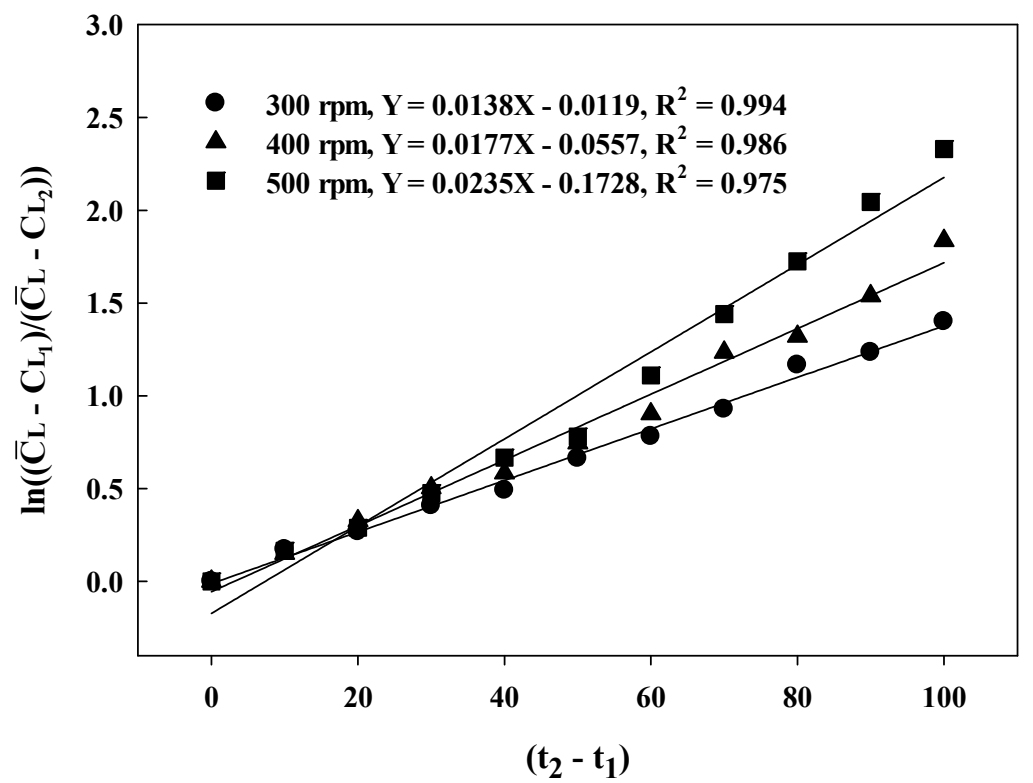

Figure 3. The volumetric mass transfer coefficient, $K_{L} a$, depends on agitation speed.

\subsection{Spore Ratio at Different Agitation Speeds}

As shown in Figure 4, spore production of B. subtilis Y9 was correlated with agitation speed. Increasing agitation speed resulted in early spore production. When agitated at $500 \mathrm{rpm}$, spores of B. subtilis Y9 were produced from $24 \mathrm{~h}$, while no spore production was observed throughout the culture at 300-400 rpm. Volumetric productivity of surfactin sharply decreased after spore appearance at $500 \mathrm{rpm}$, and remained low until the end of culture. Volumetric productivity from $12 \mathrm{~h}$ to $24 \mathrm{~h}$ was higher than $24.0 \mathrm{mg} / \mathrm{L} \cdot \mathrm{h}$ at $500 \mathrm{rpm}$, and was maintained at less than $5.0 \mathrm{mg} / \mathrm{L} \cdot \mathrm{h}$ after spore production. Under agitation at 300-400 rpm, volumetric productivity was maintained for longer than at $500 \mathrm{rpm}$. Surfactin was produced until $44 \mathrm{~h}$ at $300 \mathrm{rpm}$, and until $36 \mathrm{~h}$ at $400 \mathrm{rpm}$. 


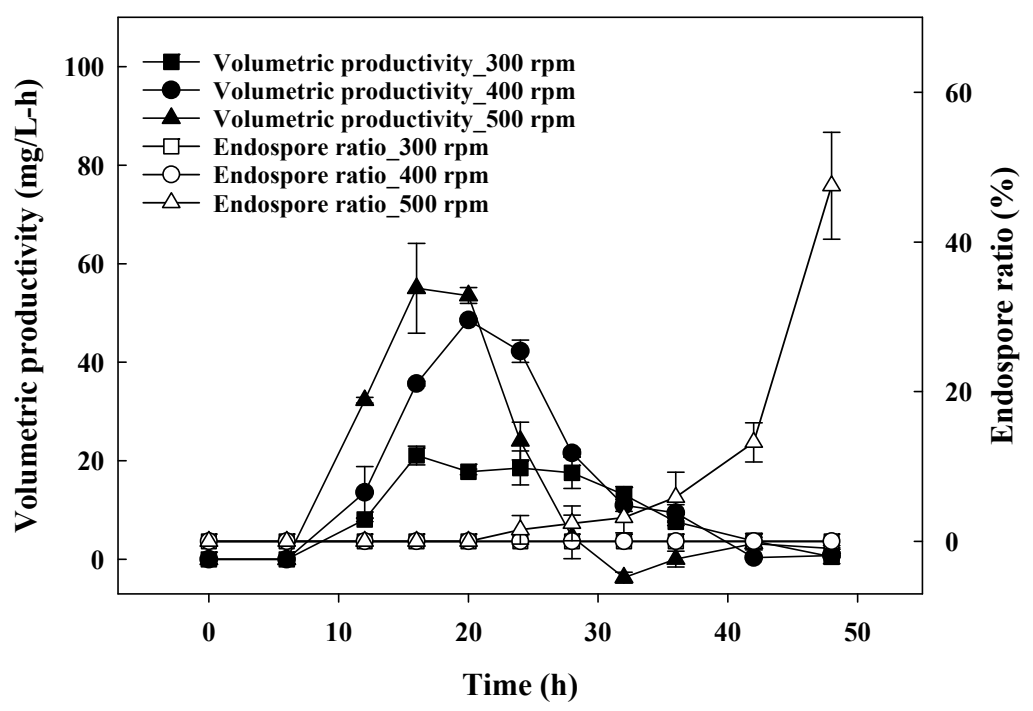

Figure 4. Profiles of volumetric surfactin productivity and spore ratio. Closed and open symbols indicate volumetric productivity and spore ratio, respectively. Cultivations were performed in $5 \mathrm{~L}$ jar bioreactors at $30^{\circ} \mathrm{C}$ for $48 \mathrm{~h}$.

\subsection{Batch-Fermentation Characteristics with a Mesh-Type Sparger}

Instead of an original-type sparger, a mesh-type sparger was installed to increase $K_{L} a$ by generating microsized air bubbles. Under agitation at $400 \mathrm{rpm}$ with the mesh-type sparger, the $K_{L} a$ was $0.0258 \mathrm{~s}^{-1}$, which was higher than of $0.0177 \mathrm{~s}^{-1}$ obtained with the original sparger at $400 \mathrm{rpm}$ (Figure 5). Volumetric productivity of surfactin from $12 \mathrm{~h}$ to $24 \mathrm{~h}$ was higher than that with the original sparger at $400 \mathrm{rpm}$ (Figure 6), resulting in the highest surfactin concentration of $875 \mathrm{mg} / \mathrm{L}$ (Figure 7). Productivity was maintained above $42.3 \mathrm{mg} / \mathrm{L} \cdot \mathrm{h}$ until $24 \mathrm{~h}$. Once spores were produced as of $36 \mathrm{~h}$, productivity dramatically dropped to $3 \mathrm{mg} / \mathrm{L} \cdot \mathrm{h}$. When the spore ratio went up to $18.8 \%$ at $48 \mathrm{~h}$, productivity even dropped to $2 \mathrm{mg} / \mathrm{L} \cdot \mathrm{h}$. Thus, the mesh-type sparger promoted $K_{L} a$, leading to an increase in volumetric productivity of surfactin in the early stage of culture.

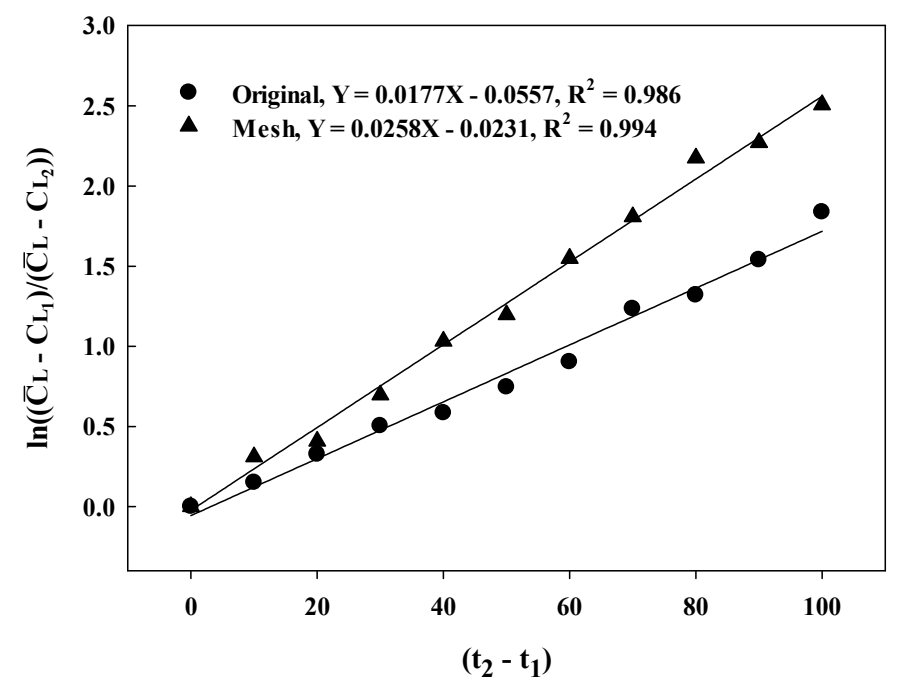

Figure 5. Volumetric mass transfer coefficient, $K_{L} a$, when an original and a mesh-type sparger were used. Cultivations were performed in $5 \mathrm{~L}$ jar bioreactors at $30^{\circ} \mathrm{C}$ at $400 \mathrm{rpm}$. 


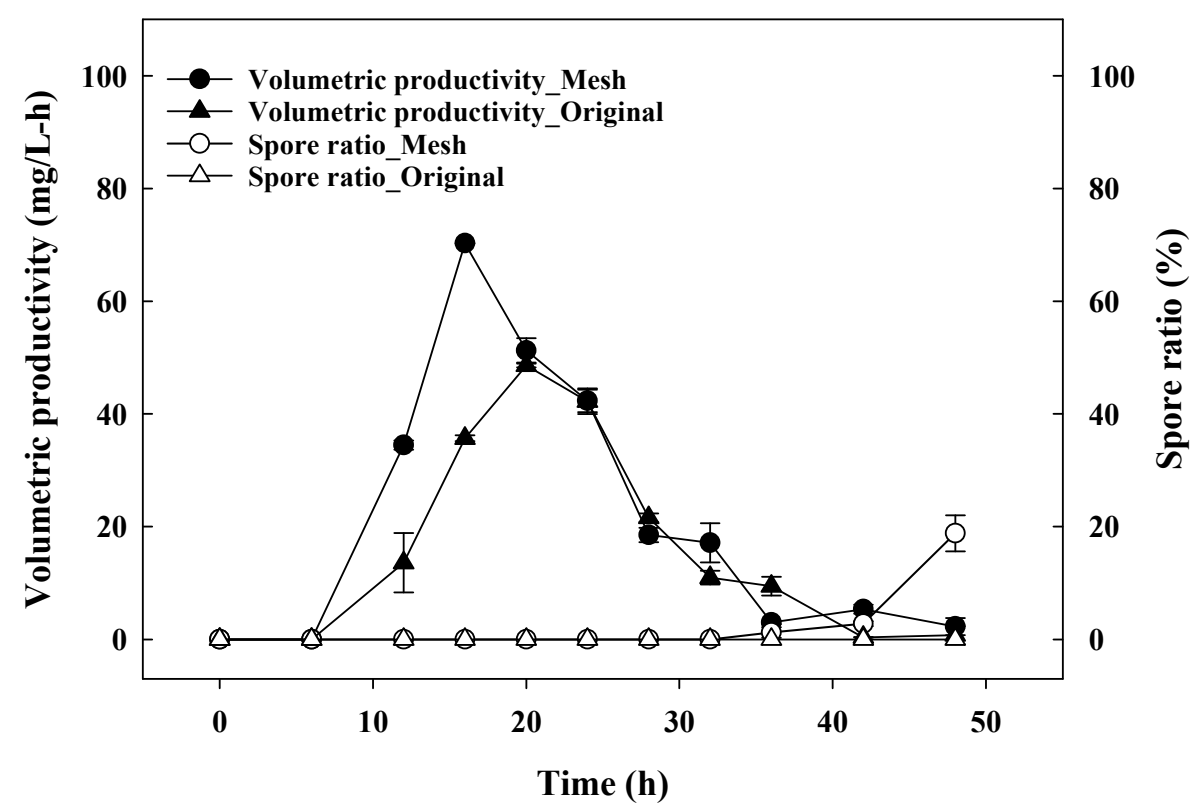

Figure 6. Profiles of volumetric surfactin productivity and spore ratio when an original and a mesh-type sparger were used. Cultivations were performed in $5 \mathrm{~L}$ jar bioreactors at $30^{\circ} \mathrm{C}$ at $400 \mathrm{rpm}$.

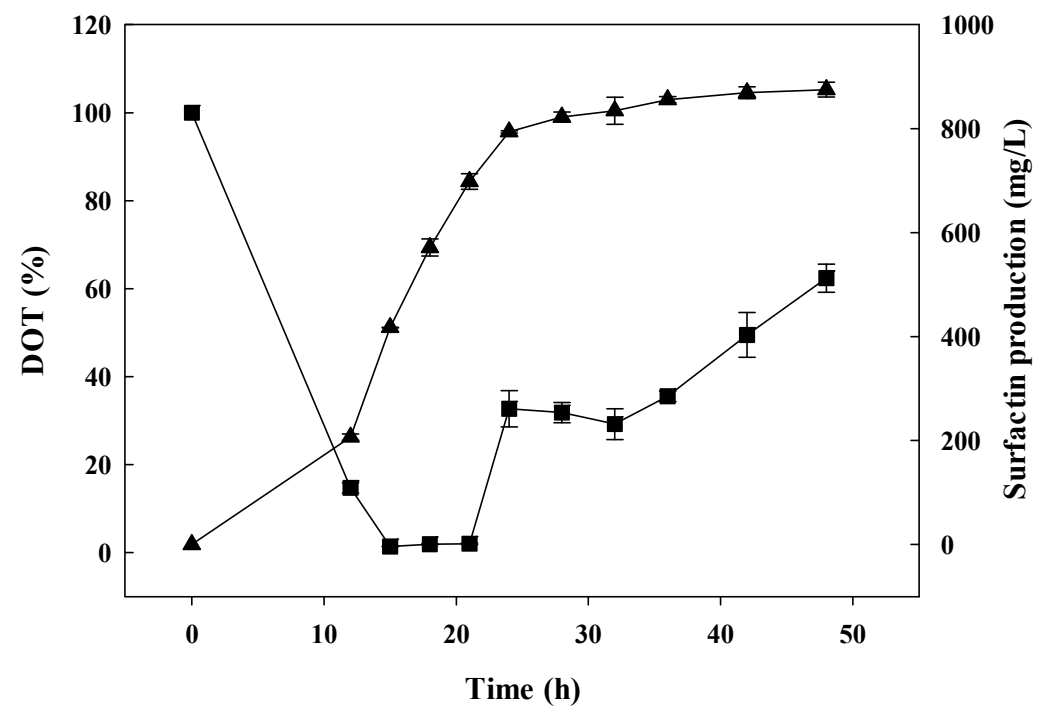

Figure 7. Surfactin production when a mesh-type sparger was used. Cultivations were performed in $5 \mathrm{~L}$ jar fermenters at $30^{\circ} \mathrm{C}$ for $48 \mathrm{~h}$.

\section{Discussion}

DOT is a critical fermentation parameter for aerobic micro-organisms to produce their metabolites. When microbial metabolite production is correlated to OUR, DOT should be maintained above a certain threshold because sufficient DOT leads to a higher OUR [15,16]. Reductions in microbial metabolite yields have been reported when DOT fell below a critical level $[17,18]$. To maintain a suitable DOT level, it is important that oxygen transfer takes place faster than oxygen uptake, especially in the log phase, when the microbial population undergoes exponential growth. Both agitation and aeration have been applied to solve this problem, elevating $K_{L} a$ in bioreactors $[10,11,19]$. In the case of surfactin production using Bacillus spp., oxygen-transfer efficacy plays an important role in production kinetics. Increases in agitation speed and aeration rate reportedly resulted in maximum surfactin production $[9,10]$. However, a reduction in surfactin production was observed at a higher agitation speed due to vigorous foam production [11]. Rapid foam formation caused the culture to overflow, resulting in decreased 
cell mass and reduced surfactin production. In our study, an increase in agitation speed led to an increase in $K_{L} a$, resulting in an increment in surfactin production. Similar to findings by Yeh et al. [11], maximal surfactin concentration was not observed at the highest agitation speed of $500 \mathrm{rpm}$, but at $400 \mathrm{rpm}$. However, the reason for avoiding high agitation speed differed in our study. Since foam formation was perfectly controlled by an antifoam agent, there was no foam formation at $500 \mathrm{rpm}$. However, high agitation speed led to early spore formation, while no spore formation was observed at low agitation speeds. Considering that the volumetric productivity of surfactin was reduced when endospores were produced, sporulation of B. subtilis $Y 9$ seems to have a negative effect on surfactin production.

Since sufficient oxygen supply is required for surfactin production, a mesh-type sparger was applied to improve the oxygen-transfer rate without increasing agitation speed. Use of the mesh-type sparger led to an increase in the gas-liquid interfacial area by generating microsized bubbles. $K_{L} a$ with the mesh-type sparger was higher than that with the original sparger, showing the highest surfactin production. Surfactin production rate from $12 \mathrm{~h}$ to $24 \mathrm{~h}$ was substantially higher than that in the case of the original sparger under all agitation speeds. Under agitation at $500 \mathrm{rpm}$ with the mesh sparger, however, endospore appearance was observed from $24 \mathrm{~h}$, resulting in a reduction in surfactin concentration to $584.0 \mathrm{mg} / \mathrm{L} \cdot \mathrm{h}$ (data not shown).

There are numerous reports that a high DOT level has a positive effect on spore production of Bacillus spp. [20-22]. The higher the oxygen supply is, especially $K_{L} a$, the higher the spore productivity [21,23]. In our study, high DOT resulted from increased agitation speed, leading to fast sporulation. Considering that sporulation might have an adverse effect on surfactin production in the submerged culture of $B$. subtilis $Y 9$, the increase in agitation speed to improve DOT level should be limited. Instead, we attempted to promote $K_{L} a$ by installing the mesh-type sparger. As shown in Figure 5, both the highest volumetric productivity and prolonged production period were observed, although sporulation started in the stationary stage of culture (1.2\% of spore ratio at $36 \mathrm{~h})$.

\section{Conclusions}

In this study, fermentation parameters for surfactin production in a submerged culture of Bacillus subtilis Y9 with various oxygen-transfer rates were optimized. In $5 \mathrm{~L}$ jar fermenters, surfactin production and OUR were positively correlated; the volumetric productivity of surfactin increased proportionally to increasing the OUR value from 0 to $250 \mathrm{~s}^{-1}$. In addition, $K_{L} a$ was positively correlated with volumetric surfactin productivity. However, a reduction in surfactin production was observed at a vigorous agitation speed, i.e., $500 \mathrm{rpm}$. The volumetric productivity of surfactin sharply decreased after spore appearance and remained low until the end of culture. A mesh-type sparger, which generates microsized air bubbles, promoted $K_{L} a$ without the need for vigorous agitation, leading to an increase in volumetric surfactin productivity in the early stage of the culture. These findings are expected to be useful in building a strategy for scaling up this fermentation process.

Author Contributions: Conceptualization, H.W.P.; methodology, S.H., H.M.K., and H.H.C.; software, J.-H.L.; formal analysis, I.M.H. and J.-H.L.; investigation, S.H., H.M.K., and H.H.C.; funding acquisition, J.-C.K., I.S.K., and H.W.P.; writing-original draft, S.H., J.-C.K., I.S.K., and H.W.P.

Funding: This research was supported by grants (315007-07) from the Korea Institute of Planning and Evaluation for Technology in Food, Agriculture, Forestry, and Fisheries (IPET), and the World Institute of Kimchi (KE1801-1), funded by the Ministry of Science and ICT, Republic of Korea.

Conflicts of Interest: The authors declare no conflict of interest.

\section{References}

1. Banat, I.M. Biosurfactants production and possible uses in microbial enhanced oil recovery and oil pollution remediation: A review. Bioresour. Technol. 1995, 51,1-12. [CrossRef]

2. Velioglu, Z.; Urek, R.O. Biosurfactant production by Pleurotus ostreatus in submerged and solid-state fermentation systems. Turkish J. Biol. 2015, 39, 160-166. [CrossRef] 
3. Raza, Z.A.; Rehman, A.; Hussain, M.T.; Masood, R.; ul Haq, A.; Saddique, M.T.; Javid, A.; Ahmad, N. Production of rhamnolipid surfactant and its application in bioscouring of cotton fabric. Carbohydr. Res. 2014, 391, 97-105. [CrossRef] [PubMed]

4. Banat, I.M.; Franzetti, A.; Gandolfi, I.; Bestetti, G.; Martinotti, M.G.; Fracchia, L.; Smyth, T.J.; Marchant, R. Microbial biosurfactants production, applications and future potential. Appl. Microbiol. Biotechnol. 2010, 87, 427-444. [CrossRef] [PubMed]

5. Seydlova, G.; Svobodova, J. Review of surfactin chemical properties and the potential biomedical applications. Cent. Eur. J. Med. 2008, 3, 123-133. [CrossRef]

6. Yang, S.Y.; Lim, D.J.; Noh, M.Y.; Kim, J.-C.; Kim, Y.C.; Kim, I.S. Characterization of biosurfactants as insecticidal metabolites produced by Bacillus subtilis Y9. Entomol. Res. 2017, 47, 55-59. [CrossRef]

7. Das, P.; Mukherjee, S.; Sen, R. Genetic regulations of the biosynthesis of microbial surfactants: An overview. Biotechnol. Genet. Eng. Rev. 2008, 25, 165-186. [CrossRef] [PubMed]

8. Shaligram, N.S.; Singhal, R.S. Surfactin-A review on biosynthesis, fermentation, purification and applications. Food Technol. Biotechnol. 2010, 48, 119-134.

9. Fonseca, R.R.; Silva, A.J.R.; De Franc, F.P.; Cardoso, V.L.; Sérvulo, E.F. Optimizing carbon/nitrogen ratio for biosurfactant production by a Bacillus subtilis strain. Appl. Biochem. Biotechnol. 2007, 137, 471-486. [PubMed]

10. Ghribi, D.; Ellouze-Chaabouni, S. Enhancement of Bacillus subtilis lipopeptide biosurfactants production through optimization of medium composition and adequate control of aeration. Biotechnol. Res. Int. 2011, 2011, 653654. [CrossRef] [PubMed]

11. Yeh, M.S.; Wei, Y.H.; Chang, J.S. Enhanced production of surfactin from Bacillus subtilis by addition of solid carriers. Biotechnol. Prog. 2005, 21, 1329-1334. [CrossRef] [PubMed]

12. Miller, G.L. Use of dinitrosalicylic acid reagent for determination of reducing sugar. Anal. Chem. 1959, 31, 426-428. [CrossRef]

13. Hussey, M.A.; Zayaitz, A. Endospore Stain Protocol; American Society for Microbiology: Wasinghton, DC, USA, 2012.

14. Bandyopadhyay, B.; Humphrey, A.E. Dynamic measurement of the volumetric oxygen transfer coefficient in fermentation systems. Biotechnol. Bioeng. 1967, 9, 533-544. [CrossRef]

15. Avignone-Rossa, C.; Arcas, J.; Mignone, C. Bacillus thuringiensis growth, sporulation and $\delta$-endotoxin production in oxygen limited and non-limited cultures. World J. Microbiol. Biotechnol. 1992, 8, 301-304. [CrossRef] [PubMed]

16. Kraemer-Schafhalter, A.; Moser, A. Kinetic study of Bacillus thuringiensis var. israelensis in lab-scale batch process. Bioprocess Eng. 1996, 14, 139-144. [CrossRef]

17. Kim, H.J.; Kim, Y.H.; Roh, Y.H.; Seong, B.L.; Shin, C.S. Optimization of enterokinase fermentation using a recombinant Saccharomyces cerevisiae. Process Biochem. 2005, 40,717-722. [CrossRef]

18. Ardestani, F.; Fatemi, S.S.; Yakhchali, B.; Hosseyni, S.M.; Najafpour, G. Evaluation of mycophenolic acid production by Penicillium brevicompactum MUCL 19011 in batch and continuous submerged cultures. Biochem. Eng. J. 2010, 50, 99-103. [CrossRef]

19. Yeh, M.S.; Wei, Y.H.; Chang, J.S. Bioreactor design for enhanced carrier-assisted surfactin production with Bacillus subtilis. Process Biochem. 2006, 41, 1799-1905. [CrossRef]

20. Boniolo, F.S.; Rodrigues, R.C.; Prata, A.M.R.; López, M.L.; Jacinto, T.; da Silveira, M.M.; Berbert-Molina, M.A. Oxygen supply in Bacillus thuringiensis fermentations: Bringing new insights on their impact on sporulation and $\delta$-endotoxin production. Appl. Microbiol. Biotechnol. 2012, 94, 625-636. [CrossRef] [PubMed]

21. Ghribi, D.; Zouari, N.; Trigui, W.; Jaoua, S. Use of sea water as salts source in starch- and soya bean-based media, for the production of Bacillus thuringiensis bioinsecticides. Process Biochem. 2007, 42, 374-378. [CrossRef]

22. Yezza, A.; Tyagi, R.D.; Valéro, J.R.; Surampalli, R.Y. Production of Bacillus thuringiensis-based biopesticides in batch and fed batch cultures using wastewater sludge as a raw material. J. Chem. Technol. Biotechnol. 2005, 80, 502-510. [CrossRef]

23. Flores, E.R.; Pérez, F; de la Torre, M. Scale-up of Bacillus thuringiensis fermentation based on oxygen transfer. J. Ferment. Bioeng. 1997, 83, 561-564. [CrossRef]

(C) 2018 by the authors. Licensee MDPI, Basel, Switzerland. This article is an open access article distributed under the terms and conditions of the Creative Commons Attribution (CC BY) license (http:/ / creativecommons.org/licenses/by/4.0/). 